\title{
TIPOLOGIAS E TENDÊNCIAS DA INCORPORAÇÃO DA AGROECOLOGIA NO ÂMBITO DO ENCONTRO NACIONAL DE GEOGRAFIA AGRÁRIA (ENGA) \\ TYPOLOGIES AND TRENDS OF AGROECOLOGY INCORPORATION UNDER THE NATIONAL MEETING OF AGRICULTURAL GEOGRAPHY (ENGA)
}

\author{
Heitor Nascimento Mendes ${ }^{1}$, Marcelo Cervo Chelotti ${ }^{1}$ \\ ${ }^{1}$ Universidade Federal de Uberlândia(UFU),Uberlândia,MG,Brasil
}

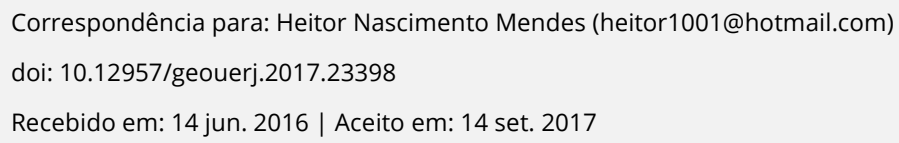

\section{RESUMO}

A partir dos trabalhos publicados nos anais do Encontro Nacional de Geografia Agrária (ENGA), fez-se uma análise qualitativa da incorporação da temática da Agroecologia no âmbito da Geografia, compreendendo as maneiras e formas com que a Geografia Agrária se inter-relaciona com a Agroecologia. Desde a edição de 2004, em que ela apareceu pela primeira vez como tema de trabalho, observou-se uma diversidade de temas sendo incorporados à discussão, de modo que foi possível estabelecer algumas tipologias referentes às várias perspectivas em que os trabalhos foram construídos. Para melhor dividir os trabalhos em eixos mais abrangentes, foram estabelecidas as tipologias: Agroecologia e Comunidades Tradicionais; Agroecologia e Educação do campo/escolar; Agroecologia e Luta pela Terra/Reforma Agrária; Agroecologia e Fundamentos Técnicos e Metodológicos; e Agroecologia e Experiências e Estudos de Caso. Essa temática aparece na Geografia Agrária ainda na década de 1990, em razão da incipiência de uma série de indagações acerca do modelo predominante na agricultura, e os trabalhos publicados nas últimas edições do ENGA demonstram a consolidação e o crescimento do debate dentro da Geografia.

Palavras-chave: Agroecologia; Geografia Agrária; Paradigma de Agricultura; Anais ENGA.

\begin{abstract}
From the papers published in the annals of the National Agrarian Geography Meeting (ENGA), a qualitative analysis of the incorporation of the Agroecology thematic in the context of geography was made, comprising the manners and ways in which Agrarian Geography interrelates with Agroecology. Since the 2004 edition, where it first appeared as working theme, it was observed a diversity of themes being incorporated into the discussion, though it is possible to establish some typologies related to various perspectives in which the works were built. In order to better divide the work into wider axles, they were established the typologies of Agroecology and Traditional Communities, Agroecology and Rural education / School, Agroecology and the Struggle for Land / Land Reform, Agroecology and Technical and Methodological Foundations, and Agroecology and Experiences and Case Studies were established. This thematic appears in Agricultural Geography still in the 1990s, due to the paucity of a series of questions about the prevailing model in agriculture, and the works published in ENGA recent editions demonstrate the consolidation and growth of the debate within the geography.
\end{abstract}

Keywords: Agroecology; Agrarian geography; Paradigm of Agriculture; ENGA Annals.

\section{INTRODUÇÃo}

As mudanças relativas à produção agrícola, principalmente em relação à distribuição de terras e aos modelos produtivos empregados, apresentam uma diversificação na estrutura rural e no espaço 
agrário. Este fato desperta uma série de possíveis análises acerca das características do desenvolvimento rural de determinada localidade, os diferentes "rumos" tomados e seus resultados.

As implicações socioespaciais dos modelos produtivos agrícolas assumem grande importância por resultarem em mudanças de acordo com suas demandas, sejam elas sociais, econômicas ou ambientais. Assim, dependendo do modelo empregado, podemos observar diferentes relações de trabalho, de mercado, com a natureza, entre outras.

No caso brasileiro, os modelos "escolhidos" e empregados no campo vão ao encontro de uma série de questões que ora foram esquecidas, ou seja, não foram respondidas ou pensadas, ora se optou por não estarem nas atas das discussões. São questões que colocam em xeque alguns mecanismos e técnicas ligados a tais modelos. Nesse processo, mantiveram-se uma estrutura agrária historicamente concentrada e o desrespeito à agricultura familiar, ao pequeno produtor e à natureza. A produção torna-se insustentável em longo prazo, pois diversas condições para que ela se mantenha acabam sendo destruídas pelo próprio modelo.

A agricultura no Brasil foi caracterizada historicamente pela existência dos latifúndios, que, desde os primórdios, produziam majoritariamente monoculturas em todo o litoral brasileiro. Passando posteriormente para o interior, cada região foi responsável pela produção de determinadas culturas, como a cana-de-açúcar e o café. A utilização de grandes extensões de terra, muitas vezes sem técnicas adequadas - desde o trabalho excessivo dos trabalhadores ao uso do solo sem grandes preocupações —, caracterizou o sistema de produção agrícola brasileiro, que, em alguns aspectos, se manteve até os dias atuais.

Porém, houve algumas mudanças significativas a partir da inserção de tecnologia e informação no campo, na chamada Revolução Verde, em meados do século XX. Ela contribuiu para a implantação e a dependência de elementos químicos e mecanização avançada no processo produtivo, promovendo grandes mudanças na produção agrícola brasileira, que, desde então, passou a ter um caráter moderno e industrial. 
Foram várias as implicações decorridas dessa modernização agrícola, o que acabou impulsionando o surgimento de indagações acerca de tal modelo alguns anos mais tarde, em uma preocupação social e ambiental ignorada pela modernização. Os modelos empregados no campo se adequaram ao projeto dos países produtores de uma indústria de base e tecnologia no pós-guerra, que era exatamente a garantia de lucro tanto para a indústria como para o latifundiário.

As diversas críticas ao modelo da Revolução Verde combatiam tais práticas, a exemplo da Agroecologia, que se fundamentou teórico-metodologicamente e se constituiu como ciência no decorrer da década de 1980. Houve assim a proposição de uma verdadeira transição agroecológica nas décadas de 1970/80, que combatia as formas de produção do modelo agora hegemônico e aquilo que se fazia necessário para mantê-lo.

Para uma maior compreensão dos processos acarretados no espaço agrário nacional, uma relação geográfica se faz necessária de modo a identificar diferentes processos de execução de uma agricultura a partir de experiências em diferentes territórios, visto que se podem entender e interpretar os diferentes resultados de cada modelo. Segundo Mendonça (2004), essa reflexão é fundamental para a Geografia, pois o que está em jogo é a defesa dos territórios (camponês, indígena, quilombola, ribeirinho, seringueiro, cerradeiro etc.). A defesa das condições de vida e de relações adequadas com a natureza é possível a partir da garantia da permanência e do acesso à terra por meio de uma reforma agrária que assegure dignidade aos trabalhadores/camponeses e que consiga incorporar os saberes da vida. Assim, deve levar em conta as especificidades do solo, do clima, dos recursos hídricos e, principalmente, os saberes-fazeres, as experiências e vivências dos sujeitos — protagonistas — da mais importante ação política deste país, qual seja, a luta pela terra e pela reforma agrária.

Tivemos, portanto, como principal objetivo identificar e analisar nos anais do Encontro Nacional de Geografia Agrária como a Agroecologia está sendo incorporada nos trabalhos publicados. Mediante o entendimento das diferentes implicações socioespaciais dos modelos produtivos utilizados no Brasil a partir da segunda metade do século XX, suas características e consequências, fizemos um paralelo com 
a ciência geográfica a partir da incorporação de estudos alternativos ao modelo da Revolução Verde, com destaque para a Agroecologia.

\section{Materiais e Metodologia}

Como estratégia metodológica, a releitura das obras que descrevem e interpretam os diferentes fenômenos resultantes dos paradigmas de agricultura - Revolução Verde e Agroecologia - nos forneceu uma maior capacidade de entendimento dos diferentes rumos do campo brasileiro até os dias atuais. Entendemos ser possível, a partir dos autores clássicos e contemporâneos, fazer uma discussão sobre os diferentes estágios do desenvolvimento agrário nacional: como foram viabilizados, suas características, consequências e permanência.

Consequentemente, tivemos maior respaldo na análise dos trabalhos publicados nos eventos, visto que vários dos autores utilizados na discussão teórica do presente trabalho estão presentes nos artigos analisados, e que suas concepções tangem o debate a todo o momento. Pudemos, assim, ter uma maior compreensão das diferentes vertentes adotadas pelos autores dos artigos.

Ao analisar os artigos publicados, tivemos acesso a informações quantitativas e qualitativas tanto dos próprios trabalhos, visto que foram divididos em tipologias e analisados a cada edição, bem como das próprias formas de execução das práticas agrícolas sustentáveis, que podem diferenciar-se de acordo com a região ou o lugar (estado, município, clima, bioma, cultura etc.). Diante do quadro nacional e da emergência de um novo paradigma de agricultura, traçamos um perfil dos trabalhos no que concerne à forma com que discutiram os diferentes aspectos, abordagens e práticas agroecológicas (tipologias), ao crescimento das publicações a cada edição e às bases teórico-metodológicas (principais autores). Desse modo, obtivemos várias informações sobre como se estão desenrolando essas experiências teóricometodológicas e práticas de Agroecologia em diferentes regiões do país. Como poderemos observar, as experiências e o escopo teórico da Agroecologia, no caso dos trabalhos geográficos, estão vinculados a diversos temas, como educação, luta pela terra e pela reforma agrária, relatos em vários estados e 
municípios do país e à denúncia do modelo vigente com vistas a diferentes formas de produção orgânica, entre outros.

Portanto, traçamos um perfil quantitativo e qualitativo de como a Agroecologia foi e está sendo trabalhada pela Geografia a partir das análises dos trabalhos publicados nos eventos.

A análise quantitativa foi realizada com base no número de trabalhos publicados a cada edição. Já na qualitativa, foram identificadas as palavras-chave que mais ocorreram, o que permitiu o acesso aos diferentes temas que aparecem relacionados à Agroecologia, para posteriormente, os trabalhos serem divididos em diferentes tipologias, por meio das quais se puderam identificar as várias formas de relação entre as duas áreas do conhecimento.

Buscaram-se nos anais dos eventos todos os artigos com a temática da Agroecologia explícita ou implícita no corpo do trabalho. Em seguida, construiu-se um gráfico para esboçar o crescimento na publicação de tais artigos a cada edição. Também identificaram-se as principais palavras-chave utilizadas, observando-se a abrangência e o crescimento de temas pouco ou não trabalhados nas primeiras edições do evento, e que hoje aparecem entre os principais, como é o caso da educação do campo.

Cinco tipologias predominantes foram definidas para os trabalhos. Como a temática da Agroecologia acabou por se dissipar entre vários temas, o que demonstra seu caráter científico e transversal, achamos importante elencar as principais vertentes em que é trabalhada nos artigos. São elas:

Agroecologia e Comunidades tradicionais: Trabalhos que descrevem as experiências agroecológicas realizadas em comunidades camponesas, quilombolas, povos ribeirinhos, indígenas, pescadores, ciganos, extrativistas e outras que preservam seus modos de vida há várias gerações, e que buscam formas sustentáveis de produção. 
Agroecologia e Educação do campo/escolar: Trabalhos que buscam metodologias para que a educação do campo/escolar leve o aluno a entender e enxergar de forma crítica a situação da agricultura, compreendendo a Agroecologia e seus fundamentos.

Agroecologia e Luta pela terra/Reforma Agrária: Experiências agroecológicas de produção em assentamentos e acampamentos rurais, onde a resistência e a luta pela terra/reforma agrária também são representadas nas formas alternativas de produção dos alimentos.

Agroecologia e Fundamentos técnicos e metodológicos: Trabalhos que descrevem métodos e técnicas produtivas sustentáveis, auxiliando o trato com a terra, os sistemas produtivos, a comercialização, enfim, todo o processo de produção, e tendo a Agroecologia como norte dessas técnicas e metodologias.

Agroecologia e Experiências e estudos de caso: Estudos acerca de experiências que tenham sido realizadas, nos quais é possível identificar como tais experiências crescem em todas as regiões, bem como os diferentes métodos e formas de produção a cada caso.

A partir dessas cinco tipologias, entendemos que os trabalhos foram agregados a eixos mais abrangentes, sem deixar de lado suas especificidades e concepções acerca da Agroecologia, nem o diálogo entre a Geografia Agrária e os temas trabalhados.

Para demonstrarmos o papel e a atuação do Estado diante do atual quadro, foram abordadas as principais formas de gerenciamento e gestão de programas e os planos e políticas públicas voltadas ao campo, hoje sob responsabilidade do Ministério da Agricultura, Pecuária e Abastecimento (MAPA) e do Ministério do Desenvolvimento Agrário (MDA). Deu-se ênfase a algumas dessas políticas voltadas à agricultura familiar e ao pequeno produtor, com vistas ao fomento da produção agroecológica.

\section{Referencial teórico-conceitual básico}


As explicações para o atual momento da agricultura brasileira, seu desenvolvimento e fundamentos, estão intrinsecamente ligadas: ao processo de reestruturação ocorrido em meados do século XX, que acabou por levar a produção no campo a uma condição subordinada em relação à indústria; e ao modo de produção capitalista, em um processo de internacionalização da atividade agrícola que tinha como pano de fundo os rumos intencionados pelos países "desenvolvidos".

Os principais pilares dessa reorganização produtiva ocorrida no país pós-Segunda Guerra evidenciam o caráter conservador e doloroso da modernização da agricultura, como destaca Graziano Da Silva (1980). Trata-se de um processo em que a ciência, a tecnologia e a informação acabam por revolucionar a produção.

Como salienta o referido autor, para responder às necessidades da incorporação da agricultura à indústria, surgiram algumas mudanças nas relações de trabalho, que preservaram ou até mesmo agravaram a concentração das terras. Simultaneamente, houve

a) Um aumento na oferta de matérias-primas e alimentos para o mercado interno sem comprometer o setor exportador que gerava divisas para o processo de industrialização, via substituição das importações;

b) A agricultura se conectou ao circuito global da economia não apenas como compradora de bens de consumo industriais, como também houve o que podemos chamar de uma verdadeira "industrialização da agricultura", na medida em que esta passou a demandar quantidades crescentes de insumos e máquinas geradas pelo próprio setor industrial. (GRAZIANO DA SILVA, 1980, p. 30).

Por conta da infinidade de produtos químicos e tecnologias empregados, a produção por hectare aumentou, rompeu barreiras naturais que impossibilitavam um crescimento produtivo de tal porte e transformou de vez os sistemas agrícolas. A agricultura então se globalizou e o ciclo econômico se estruturou, passando a receber produtos da indústria (inseticidas, fertilizantes, maquinários dentre outros.) e aumentando a oferta de matéria-prima. Isto porque o combate às pragas, a correção dos solos e o uso de máquinas, como tratores e colheitadeiras, garantiram o lucro dos grandes capitais "dentro e fora da porteira". 
Como salienta Elias (2003), o estreitamento de relações entre a produção agrícola e o restante da economia constitui um importante fator quando se quer distinguir a agricultura contemporânea daquela existente antes da revolução tecnológica. Foi justamente em razão dessa aproximação que a agricultura se subordinou aos ditames do grande capital, e que a terra como fonte de vida, a "terramatéria", acabou por se transformar em fonte de lucro, em "terra-mercadoria". O resultado é exatamente uma dependência da produção agrícola ao processo produtivo como um todo, com um grande agravante: a forma como a terra está distribuída. A apropriação histórica da terra explica em grande parte a concentração apresentada naquele período e que ainda podemos observar nos dias atuais.

Os rumos tomados pela agricultura se vinculam intimamente às diretrizes industriais discutidas e propostas para o país nas décadas seguintes (pós-Segunda Guerra). A necessidade de industrialização e os esforços para que ela ocorresse foram direcionados a substituir as importações, fomentando a indústria de maquinários e elevando a produção agropecuária.

O processo de "industrialização da agricultura" demonstra a verdadeira reestruturação produtiva em curso no campo brasileiro, e isso era exatamente o que propunham os países detentores da tecnologia necessária para a viabilização do modelo: suas empresas seriam fornecedoras de todo o pacote necessário à produção.

De acordo com essas diretrizes, a agricultura brasileira se incorporaria ao que chamamos de Revolução Verde. Essa nova transição da agricultura nacional se baseava no grande crescimento populacional para justificar o uso desenfreado da tecnologia no campo. Com o pretexto de que faltariam alimentos caso não houvesse uma mudança drástica na forma de produzir, e de que a elevação da produção seria possível apenas com o uso dos produtos vindos da indústria, a Revolução Verde acabaria por introduzir pacotes que eliminariam a necessidade de o produtor se adequar ao ritmo da natureza, permitindo-lhe fazer uso de técnicas e produtos que relegariam as condições naturais a um segundo plano no processo. Isso garantia o lucro das indústrias por exigir uma mão de obra cada vez menor, havendo portanto liberação de mão de obra para a produção fabril nas cidades, o que aumentaria a produção e garantiria 
matéria-prima em abundância após a colheita. Enfim, o capital controlaria agora todo o processo, fecharia o ciclo e abriria espaço para o movimento de fusão de capitais que marca os complexos agroindustriais surgidos posteriormente.

Várias foram as consequências disso em curto prazo e, em um período de tempo maior, as coisas tendem a piorar. A agricultura no Brasil esteve marcada por características que deixam o trabalhador em condições extremas de trabalho, sempre sujeito às demandas de uma estrutura agrária extremamente concentrada, guiada por uma dicotomia entre capital e trabalho. 0 trabalhador recebe um tratamento que está aquém da sua importância na produção, o que ocasiona diversos problemas relacionados às suas condições e saúde.

Porém, o legado deixado seria algo um tanto quanto trágico. Os problemas sociais resultantes da nova ordem se somavam a uma crescente concentração de terras, a políticas de crédito e de incentivo que atendiam a demandas vindas apenas daqueles que estavam de acordo com a produção Verde, a um sindicalismo enfraquecido, enfim, à capacidade de alguns em gerar muita renda, porém concentrada, em detrimento de outros, que iam em busca dela nas cidades.

Não bastasse, os caminhos traçados naquele momento iriam jogar toneladas de produtos químicos no alimento, no solo, nos cursos d'água e no ar, em um processo de degradação ambiental e alimentícia nunca visto na história da humanidade. Juntas, a agricultura e a indústria banalizaram a natureza. Os incontáveis problemas ambientais acarretadas pela agricultura destruíram e continuam a destruir ecossistemas inteiros, mudando microclimas e transformando a atmosfera terrestre, pois uma árvore que cai é uma gota que seca. Os solos estão se empobrecendo e, em muitos lugares, os processos de desertificação são vistos com clareza, resultados muitas vezes de uma monocultura (voltada para a 0 mercado externo) extenuante para aquilo que a natureza demorou muito tempo para moldar. Soma-se a isso a qualidade do alimento que chega até o consumidor, com grandes quantidades de produtos químicos e alterações genéticas. Ao entrar no sistema, o produto não só afeta a própria planta, mas também o solo, cursos d'água e a própria fauna, incluindo peixes e aves. 
[...] A agricultura química considera o solo como suporte para a planta porque o resto ela fornece: adubo, água, pesticidas, herbicidas. Ou seja, não é preciso o solo trabalhar. Temos um solo morto e como resposta a isso nos apresentam a destorroadeira. Mas o solo destorroado quando recebe uma chuva tem erosão em muita parte. E a soja, por exemplo, pode nem nascer porque a crosta é de tal maneira dura que ela não consegue quebrá-la. Vê-se a crosta na superfície.

Em um solo morto, a raiz praticamente não consegue entrar e a terra está completamente anaeróbica e, se não tem ar, a planta também não funciona bem, porque ela precisa de oxigênio no ponto vegetativo e este oxigênio, quando não retirado do ar, é retirado do solo. (PRIMAVESI, 2012, p. 13).

Observa-se como é cíclico o processo de degradação ocorrido a partir dessas práticas, principalmente em relação ao solo e aos corpos d'água, como é o caso do lençol freático e de córregos e rios.

As lavouras de monoculturas levam o solo a uma escassez nutricional e baixa capacidade de trabalho, pois os produtos químicos fazem o serviço da natureza. O crescimento dessas lavouras demonstra como tal modelo vem degradando alguns biomas brasileiros, como o Cerrado, a Mata Atlântica e a Amazônia.

\section{O papel do Estado brasileiro na consolidação das políticas agrícolas}

A partir da introdução do modelo da Revolução Verde no país, o Estado brasileiro atuou de modo a limitar o produtor rural, deixando-o sem alternativas em relação à sua própria forma de produzir. A partir da criação do Sistema Nacional de Crédito Rural (SNCR), foram subsidiados praticamente todos os componentes necessários à adequação das propriedades ao processo de modernização. Entre os apoios fornecidos para viabilizar aos produtores tal reestruturação, o Estado

subsidiou a compra de máquinas e equipamentos, insumos químicos, sementes melhoradas, custeou a produção, garantiu os preços mínimos, promoveu a eletrificação rural, construiu armazéns e silos para estocar a produção, subsidiou a exportação, isentou de impostos as indústrias nascentes associadas à agricultura moderna, promoveu o seguro agrícola e etc. (ELIAS, 2003, p. 66).

Podemos destacar também, com base em Hespanhol (2008), a administração de um aparato institucional que apoiava essa modernização e que atuava em várias esferas de governo, como: a) a criação do Estatuto dos Trabalhadores Rurais (1963) e do Estatuto da Terra (1964); b) a concessão 
de crédito subsidiado por meio do Sistema Nacional de Crédito Rural (1965); c) o investimento em pesquisa agronômica e extensão rural, favorecendo a disseminação do modelo produtivista; d) a política fundiária, valorizando a propriedade privada atrelada ao mercado de terras e, ao mesmo tempo, controlando ou intervindo nos movimentos sociais de trabalhadores rurais.

A partir desse momento, o campo brasileiro acabou por se esvaziar, expulsando milhares de pessoas para as novas regiões de fronteira agrícola ou para os grandes centros urbanos industrializados. Surgiu também uma grande massa de trabalhadores temporários, os chamados boias-frias.

Ainda de acordo com a autora, a Agroecologia poderia proporcionar as bases científicas para apoiar 0 processo de transição agroecológica, possibilitando o surgimento de outras formas de agricultura sustentáveis, tais como a ecológica, a orgânica, a biodinâmica, a regenerativa, a de baixos insumos externos, a biológica e outras.

Como demonstra Altieri (2004), as críticas à agricultura e ao ideário da Revolução Verde geraram uma série de manifestações sociais que se intensificaram a partir de alguns fatos gerais, destacando que

\footnotetext{
A crise agrícola-ecológica existente, hoje, na maior parte do terceiro mundo, resulta do fracasso do paradigma dominante de desenvolvimento. As estratégias de desenvolvimento convencionais revelaram-se fundamentalmente limitadas em sua capacidade de promover um desenvolvimento equânime e sustentável. Não foram capazes nem de atingir os mais pobres, nem de resolver o problema da fome, da desnutrição ou as questões ambientais. As inovações tecnológicas não se tornaram disponíveis aos agricultores pequenos ou pobres em recursos em termos favoráveis, nem se adequaram às suas condições agroecológicas e socioeconômicas. (CHAMBERS e GHILDYAL,1985 apud ALTIERI, 2004, p. 19).
}

A Agroecologia é uma área do conhecimento que busca a integração entre as diferentes esferas sociais e áreas do conhecimento, a ênfase na produção familiar e no desenvolvimento sustentável, o aproveitamento dos recursos naturais dentro de suas capacidades, a não exclusão dos processos naturais a partir do uso de insumos e a inclusão do pequeno produtor. Enfim, é uma área que leva em consideração o caráter social, econômico e ambiental. 
Os programas e políticas vigentes do governo federal, ligados principalmente ao Ministério do Desenvolvimento Agrário (MDA) e ao Ministério da Agricultura, Pecuária e Abastecimento (MAPA), apresentam-nos algumas possibilidades frente às demandas dos movimentos sociais e à necessidade de atuação dessas esferas na resolução de problemas que já se tornaram históricos no país. As diretrizes, formas de atuação e algumas das políticas desses ministérios demonstram o que é prioridade para cada um, o que o Estado privilegia e quais os mecanismos utilizados para atingir seus objetivos por meio da constituição de secretarias, institutos, planos, programas etc.

O MAPA, de acordo com a descrição encontrada no portal do ministério,

é responsável pela gestão das políticas públicas de estímulo à agropecuária, pelo fomento do agronegócio e pela regulação e normatização de serviços vinculados ao setor. No Brasil, o agronegócio contempla o pequeno, o médio e o grande produtor rural e reúne atividades de fornecimento de bens e serviços à agricultura, produção agropecuária, processamento, transformação e distribuição de produtos de origem agropecuária até o consumidor final. (MAPA, 2015).

Vê-se explicitamente a principal vertente de atuação do ministério: o fomento ao agronegócio, proporcionando maiores facilidades para o setor em detrimento da agricultura familiar. Com sua gestão, busca integrar os vários aspectos relacionados à produção agropecuária, como comercialização, meio ambiente, organização do setor etc.

Dividido em cinco secretarias e 27 superintendências estaduais, além de laboratórios e institutos sob sua coordenação, o ministério atua por meio dos diferentes setores do agronegócio nacional, como defesa, relações internacionais, produção, desenvolvimento agropecuário, cooperativismo e políticas agrícolas. Um conjunto de ações voltadas para o planejamento, o financiamento e o seguro da produção constitui a base da Política Agrícola do Ministério da Agricultura. Por meio de estudos na área de gestão de risco, linhas de créditos, subvenções econômicas e levantamentos de dados, o apoio do estado acompanha todas as fases do ciclo produtivo. Essas ações se dividem em três grandes linhas de atuação: gestão do risco rural, crédito e comercialização. (MAPA, 2015).

Essas políticas realizam estudos e disponibilizam créditos, viabilizando a produção pela compra de insumos e maquinários, construção de armazéns, comercialização etc.

Assim, os principais planos e programas estão vinculados ao que é privilegiado pelo Estado brasileiro desde a reestruturação produtiva, e o agronegócio é realmente o carro-chefe das políticas públicas de 
apoio ao produtor rural nessa pasta. À Agroecologia não se faz referência direta, porém entende-se que o apoio a práticas sustentáveis pode alavancar tais processos produtivos, se firmado e realizado de acordo com as reais necessidades do produtor rural.

Diante desse quadro, ficam a cargo do MDA as principais políticas voltadas à agricultura familiar e sustentável no país. São vários os programas e ações promovidas pelo ministério, que têm como principal objetivo

\footnotetext{
Promover a política de desenvolvimento do Brasil rural, a democratização do acesso à terra, a gestão territorial da estrutura fundiária, a inclusão produtiva, a ampliação de renda da agricultura familiar e a paz no campo, contribuindo com a soberania alimentar, o desenvolvimento econômico, social e ambiental do país. [...] Ser reconhecido nacional e internacionalmente como ator fundamental na construção de um meio rural com equidade, com mais oportunidades de renda e vida, mais humano, com inclusão produtiva e social e respeito ao meio ambiente. (MDA, 2015).
}

Pode-se observar o quão diferentes são os papéis atribuídos a essa pasta em relação ao MAPA, pois se destacam outros valores relativos à produção agropecuária e à vida no campo.

Em um compromisso bem mais democrático, o MDA se mostra o principal responsável por programas e planos que visem a uma agricultura sustentável e ao respeito à vida, como o Programa Nacional de Fortalecimento da Agricultura Familiar (PRONAF) e o Plano Nacional de Agroecologia e Produção Orgânica (PLANAPO). Porém, o que observamos é uma capacidade de atuação diminuída em razão do privilégio dado às commodities de exportação, vinculadas à produção em larga escala e à utilização de grandes extensões de terra. Privilégio esse que desrespeita o pequeno agricultor e as diferentes possibilidades de agricultura inerentes a vários povos e culturas.

O MDA é composto por quatro secretarias além da executiva. Uma delas, a Secretaria da Agricultura Familiar (SAF), apresenta três departamentos; já as outras - a Secretaria de Reordenamento Agrário (SRA), a Secretaria do Desenvolvimento Territorial (SDT) e a Secretaria Extraordinária de Regularização Fundiária na Amazônia Legal (SERFAL) - atuam por meio de apenas um departamento. São subordinados a esse ministério o Instituto Nacional de Colonização e Reforma Agrária (INCRA) e as Delegacias Federais de Desenvolvimento Agrário. 
Entre as várias ações e programas vinculados ao ministério, principalmente à SAF, podemos citar o já referido Programa Nacional de Fortalecimento da Agricultura Familiar, o PRONAF, que financia projetos individuais ou coletivos que possam gerar renda aos agricultores familiares e assentados da Reforma Agrária, com baixas taxas de juros nos financiamentos rurais. Esses financiamentos podem servir para investimentos em máquinas, equipamentos ou infraestrutura de produção e serviços agropecuários ou não. (PORTAL DOS MINISTÉRIOS, 2015)

É possível observar a diferença de diretrizes entre os dois ministérios, bem como a dificuldade de se relacionarem. Isto porque, em se tratando do mesmo espaço agrário, são várias as possíveis dificuldades encontradas principalmente pelas políticas voltadas à agricultura familiar e ao pequeno produtor em um território marcado pela atuação e conformação do Agronegócio.

Reside aqui um dos grandes problemas da questão agrária nacional no âmbito das políticas públicas: justamente o fato de instâncias governamentais distintas tratarem o mesmo assunto de formas discrepantes, como dois lugares distintos, duas realidades. Há pouco diálogo e convergência entre as propostas, além da já referida preferência por modelos tradicionais sob o domínio de grandes Complexos Agroindustriais (CAI).

Não se tem a intenção, no presente trabalho, de analisar como está sendo a atuação dessas ações e programas no país ou em alguns casos, e sim de compreender como as políticas estão estruturadas e se levam em consideração a realidade das dificuldades enfrentadas no campo brasileiro.

O governo brasileiro, a partir da criação da Política Nacional de Agroecologia e Produção Orgânica (PNAPO), firmou o compromisso de promover um maior desenvolvimento sustentável no campo, ampliando e efetivando ações que levassem à prática de modelos com esse viés, e respondendo às preocupações dos movimentos sociais e da sociedade no geral em relação à produção de alimentos saudáveis e à preservação da natureza e dos recursos naturais. 
A política tem como principal objetivo ampliar e fortalecer a produção, a manipulação e o processamento de produtos orgânicos e de base agroecológica. Para induzir esse processo de transição na agricultura nacional, o Plano Nacional de Agroecologia e Produção Orgânica e o Plano Brasil Agroecológico buscam implementar programas e ações que viabilizem essa produção sustentável.

As metas e iniciativas reforçam esse objetivo:

As metas e iniciativas do Brasil Agroecológico são destinadas a fortalecer as redes de produção, aumentar a oferta de Assistência Técnica e Extensão Rural (ATER) com foco em práticas agroecológicas, ampliar o acesso à água e a sementes, fortalecer as compras governamentais de produtos e ampliar o acesso ao consumidor de alimentos saudáveis, sem uso de agrotóxicos ou transgênicos na produção agrícola, fortalecendo assim, economicamente, as famílias agricultoras. (MDA, 2015).

Vemos como é importante a existência da política e de seus planos e programas, apoiando e oferecendo possibilidades àqueles que foram esquecidos mediante os processos ocorridos no país. No entanto, a capacidade de aplicação dessas ações pode ser prejudicada pelo privilégio oferecido a outros setores e atividades.

A política reforça e dá voz aos vários movimentos que lutam para que outras questões possam ser pensadas e outras práticas e saberes possam ser incorporados à agricultura nacional, mas a opção por um modelo produtor de commodities para exportação, com o Agronegócio como grande carro-chefe, é nítida no momento da execução de tais políticas.

Quanto ao PRONAF, o programa tem como principal objetivo o financiamento de projetos individuais ou coletivos que possibilitem a geração de renda aos agricultores familiares e assentados da Reforma Agrária, com baixas taxas, seja para investimento em máquinas, insumos, infraestrutura, serviços ou outros. A partir da decisão sobre o que será financiando, o agricultor deve procurar os sindicatos rurais ou alguma empresa de Assistência Técnica e Extensão Rural (ATER) para obter a Declaração de Aptidão ao PRONAF, que será emitida de acordo com a renda anual e as atividades realizadas pelo agricultor. Ele será então direcionado para determinadas linhas de crédito, de acordo com suas necessidades. (PORTAL DOS MINISTÉRIOS, 2015). 
Essas linhas estão de acordo com o que se quer financiar na produção - aspectos relativos à comercialização, infraestrutura, manutenção, entre outros, e relacionados a vários tipos e formas de produção.

São várias as possibilidades de financiamento por meio das linhas, e o apoio à Agroecologia e a formas alternativas de produção se mostra inerente à constituição da política. É de grande importância para a agricultura familiar que se tenha apoio para essas práticas e que elas sejam oferecidas de forma democrática. A exemplo dos assentamentos da Reforma Agrária, alguns segmentos enfrentam diversas dificuldades de acesso a tais apoios e, desse modo, observamos como a simples existência da política não garante a real efetividade dos projetos.

O que observamos ainda hoje é o privilégio dado às commodities para o mercado externo, principalmente pelo Ministério da Agricultura, Pecuária e Abastecimento (MAPA), mas a crescente demanda e luta se somam a essa negligência de modo a fortificar todo o movimento.

\section{Resultados e discussões: a abordagem agroecológica nos anais do Encontro Nacional de Geografia Agrária (ENGA)}

Diante da realidade do campo brasileiro, estruturado a partir de dois paradigmas de agricultura, buscamos realizar uma análise com base na interface entre Geografia e Agroecologia, ou seja, buscamos entender como essas duas áreas do conhecimento estão dialogando entre si diante de duas perspectivas bem definidas.

Os trabalhos analisados foram publicados nas últimas seis edições do Encontro Nacional de Geografia Agrária (ENGA), podendo assim nos demonstrar essa inter-relação a partir da consolidação do debate na ciência geográfica no século XXI.

O evento é realizado desde 1978, e vários temas ocuparam lugar de destaque a cada edição ou período. Porém, os autores que sustentam a discussão hoje foram responsáveis por dar os primeiros passos ao 
introduzirem essa discussão nos eventos da década de 1990. Assim, levou um tempo para que a Agroecologia fosse realmente trabalhada com mais força e se disseminasse pelos diferentes temas da Geografia Agrária.

O XVII ENGA, realizado em 2004 na cidade de Gramado (RS) foi a primeira edição citada nas análises. Nela observamos uma maior difusão do debate, antes realizado apenas por alguns autores, por diferentes áreas e temas da Geografia Agrária. Foram esses autores que deram respaldo aos vários trabalhos escritos a partir de então.

Foram seis os eventos analisados (edições de 2004, 2006, 2008, 2010, 2012 e 2014) e mais de 50 artigos escritos sobre a temática, sendo que na edição de 2004 houve apenas um (nas circunstâncias colocadas).

O gráfico 01 apresenta o número de trabalhos sobre a temática Agroecologia inscritos no ENGA de 2004 a 2014. Pode-se observar o crescimento das pesquisas principalmente nas últimas edições, o que mostra que a Geografia Agrária está incorporando a discussão progressivamente.

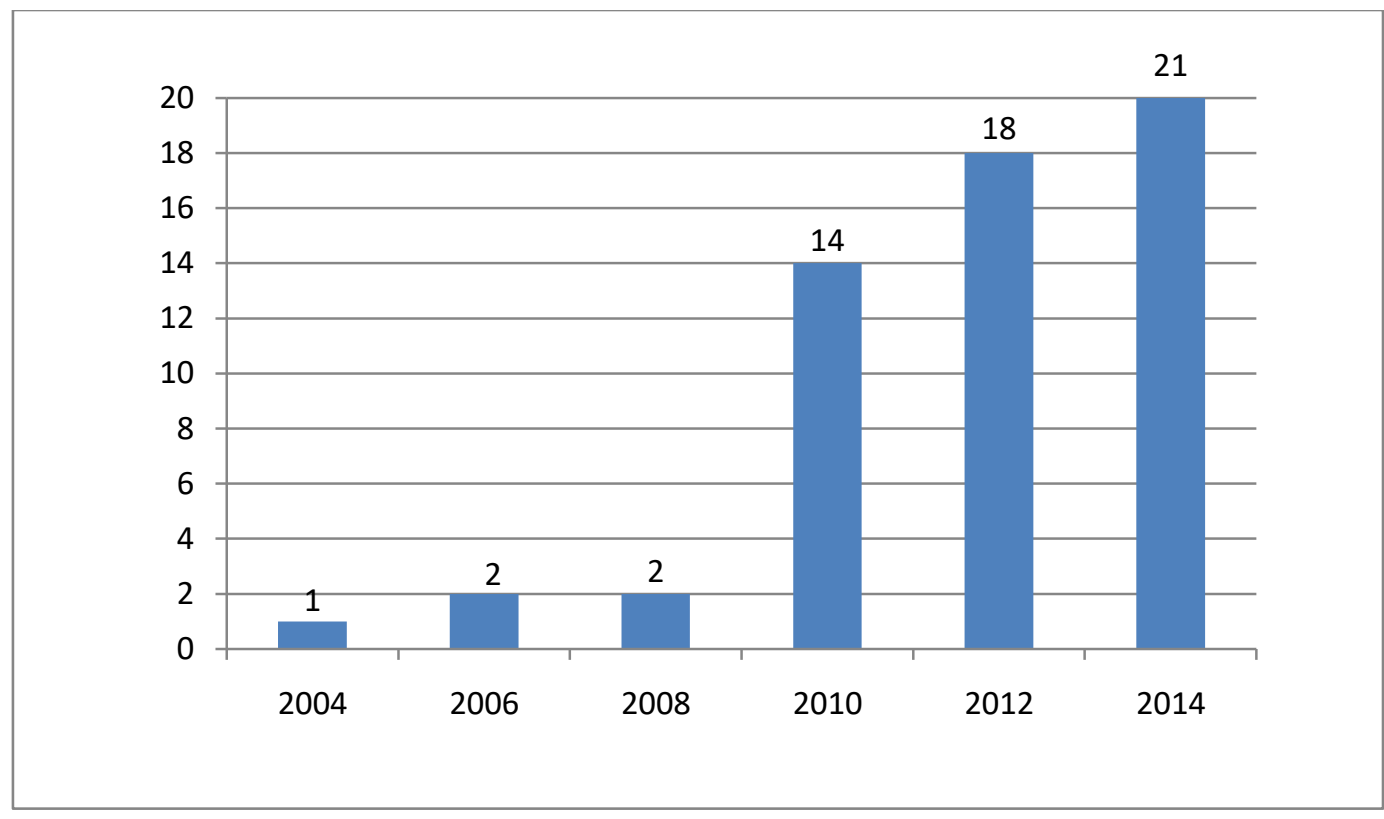

Gráfico 01: Números de publicações com temática Agroecologia nos anais do ENGA.

Fonte: anais ENGA. Org: Os autores,2015 
Além do crescimento no número de trabalhos, podemos observar como o debate da Agroecologia se estendeu para diversos temas da Geografia Agrária. O número de palavras-chave aumentou gradativamente nos eventos e passou a abranger diferentes áreas. Isto demonstra um salto qualitativo nas pesquisas realizadas, pois entendemos que essa diversificação, essa busca por diferentes possibilidades de entender a dinâmica do campo, representa um maior esforço em encontrar soluções alternativas para a produção agrícola nacional, bem como o caráter interdisciplinar da Agroecologia. Entre as palavras-chave mais recorrentes, estão exatamente "Agroecologia", "agricultura alternativa", “desenvolvimento rural", "desenvolvimento sustentável” e "modernização da agricultura".

Há também um aumento no número de autores citados nas últimas edições, comprovando mais uma vez que a temática vem sendo trabalhada de forma mais abrangente com o passar dos anos. Autores como Altieri e Caporal estiveram presentes nas citações de forma mais significativa, porém autores como Hespanhol, Gliessman, Candioto e outros foram mais citados recentemente e demonstram a atual abrangência da temática. No último evento, realizado em 2014, alguns autores que ainda não haviam sido citados apareceram de forma mais incisiva na discussão, como Milton Santos e Paulo Freire, o que demonstra novamente que o tema está sendo discutido a partir de diferentes perspectivas e com autores clássicos da Educação e da Geografia política e econômica.

Para compreendermos melhor a forma como a Geografia está trabalhando a Agroecologia, fizemos uma releitura dos principais autores que fundamentaram a discussão no Brasil. A partir das análises, pudemos observar que alguns deles foram pioneiros e ainda hoje são mencionados na discussão. Apesar de as citações terem aumentado nos últimos eventos, identificamos que Miguel Altieri, Francisco Roberto Caporal, José Antônio Costabeber e Stephen R. Gliessman deram suporte às discussões posteriores.

Diante das perspectivas de destaque identificadas nos principais autores, analisamos e dividimos os trabalhos nas cinco tipologias já descritas anteriormente. A partir dessa divisão, pudemos identificar como os trabalhos se encaixaram em diferentes temáticas relacionadas à Geografia Agrária, bem como 
a(s) tipologias que mais recorreram. Essa análise mostrou um maior direcionamento de tais pesquisas para um ou outro tema e deixou mais perceptível a relação entre Geografia e Agroecologia.

\section{Agroecologia e Comunidades Tradicionais}

As comunidades tradicionais representam uma das principais fontes de fortalecimento da agricultura familiar, e a busca por formas alternativas de produção é muito importante para que essas populações adquiram seu alimento e o seu sustento.

Entre os eventos analisados, foram identificados oito trabalhos que buscaram descrever experiências diferenciadas realizadas nessas comunidades, a maioria de famílias camponesas. A maior parte desses artigos identifica as características dessa produção em determinadas regiões do país, como as comunidades do norte de Minas, da Paraíba e de Goiás, buscando entender como está sendo oferecido apoio para tais comunidades e como é realizada a produção. As técnicas utilizadas e as concepções mudam de região para região, mas sempre apresentam um caráter de resistência, visto que as comunidades, com o apoio das universidades, realizam uma produção condizente com a realidade local. Há, portanto, a busca por uma territorialidade a partir da compreensão das concepções agroecológicas, identificando suas funções tanto ambiental como social.

Alguns trabalhos apresentam recortes maiores na intenção de analisar a questão de forma mais ampla, por exemplo, enfocando unidades federativas ou regiões inteiras. Como exemplo, podemos citar o artigo de Aline Barboza de Lima, intitulado "Agroecologia: Um olhar sobre as práticas camponesas na Paraíba", que busca um olhar sobre essas experiências em todo o estado nordestino, atentando para as comunidades que realizam esse tipo de produção e o apoio dado a elas. Já Ana Ivania Alves Fonseca, Erico Fabiano Rocha Reis e Leonardo Ferreira Gomes escreveram um trabalho que busca apresentar algumas tradições agroecológicas presentes nas populações tradicionais do norte de Minas Gerais, em “As tradições agroecológicas nas populações tradicionais do norte de Minas”analisa os meios pelos quais elas permanecem e resistem em face das várias dificuldades encontradas na região. 
Em outra vertente, o trabalho de Leonardo Oliveira Carneiro e Júlio Cesar Pereira Monerat, "Por uma Geografia do oprimido: sobre pesquisa e extensão agroecológica em uma comunidade quilombola", descreve as dificuldades a produção agroecológica em tal comunidade, seus desafios e perspectivas, bem como a reciprocidade fornecida pela extensão universitária em relação aos conhecimentos e técnicas aplicadas nesse território.

Além dos exemplos vistos nas comunidades, dois trabalhos publicados na última edição atentam para o uso sustentável de determinados biomas do país, como a Caatinga e o Cerrado, analisando as melhores técnicas e formas de se produzir nesses ambientes, suas características para um melhor aproveitamento agroecológico etc.

Assim, observamos que, além das experiências de caso em diferentes comunidades, os trabalhos também englobam as questões ambientais de cada região. Identificando as características das comunidades e dos recursos disponíveis, examinam como essas comunidades podem conseguir um melhor aproveitamento de suas áreas a partir de produções que não percam de vista as questões ambientais e sociais.

Entre as cinco tipologias, o tipo de trabalho citado acima não foi o mais numeroso, mas o crescimento desse tipo de pesquisa é evidente e se mostra de grande importância para entendermos as diferentes perspectivas e formas de produção nessas comunidades e nas diferentes regiões do país.

\section{Agroecologia e Educação do campo/escolar}

Nas primeiras edições, apesar de a questão educacional aparecer com certa ênfase, não foi identificado nenhum trabalho diretamente relacionado ao tema. Houve, sim, alguns apontamentos sobre como se deveria dar a educação do campo, como deveria incorporar a Agroecologia no currículo entre outros. Já na edição de 2014, quatro trabalhos foram identificados nessa tipologia, dos quais dois são estudos de caso: um na região da bacia do rio Caldas, de autoria de Benjamim Pereira Vilela e Andréa Pereira dos Santos, intitulado "Territórios identitários da bacia do Rio Caldas: uma proposta de educação 
ambiental e leitura"; e outro em um assentamento em Rio Verde (GO), de Franciane Prado Gonçalves, Tatiane Rodrigues de Souza e João Batista Pereira Cabral, intitulado "A concepção sobre educação ambiental no assentamento Rio Verdinho, município de Rio Verde/GO". Os trabalhos expõem as formas de se trabalhar a educação ambiental e agroecológica nessas localidades, os trabalhos realizados e a importância da presença da Agroecologia, atentando para o uso sustentável das regiões em que esses alunos vivem.

Os dois outros trabalhos enfocam a formação socioambiental de crianças e jovens do campo, conjuntamente com algum trabalho realizado.

Assim, vemos que apesar de ser intrínseco à educação do campo trabalhar tais questões, ainda lhe resta muito a fazer quanto à preparação dos alunos para a produção no campo. Isto porque ainda predomina o modelo de monocultura e a falta de contato com outros modos de produção mais condizentes com o meio ambiente e a sociedade, de modo que muito da possibilidade de mudança necessária ao campo brasileiro se perde. Entretanto, o último evento demonstra que já há a preocupação com essa questão, e a tendência é que cresça o número de trabalhos e a abrangência dos temas para as várias áreas do conhecimento.

\section{Agroecologia e Luta pela terra/Reforma Agrária}

As formas alternativas de produção no campo também são incorporadas pelos movimentos sociais como forma de resistência e luta pela terra e pela reforma agrária, buscando diferentes maneiras de cultivar e comercializar os alimentos a partir de técnicas e métodos que levem em consideração a condição do ambiente e de todos que ali vivem.

$\mathrm{Na}$ busca pela sustentabilidade ecológica, vários assentamentos e acampamentos rurais apresentam práticas que podem mudar a condição de vida da população. Vários trabalhos foram escritos desde os primeiros eventos no intuito de apresentar e justificar, a partir de mudanças na relação de trabalho e no trato com a terra, a produção agroecológica nesses locais. 
Alguns trabalhos apresentam uma discussão mais abrangente, não se detendo em um caso ou experiência específica. Um exemplo é o de Carolina Bonelli, “Agroecologia para um projeto de Reforma Agrária sustentável", em que a autora demonstra a importância da Agroecologia e da agricultura sustentável como instrumentos de luta dos movimentos sociais. No entanto, a grande maioria dos artigos apresenta experiências já realizadas em assentamentos do MST espalhados por todo o país.

Entre os trabalhos que apresentam casos específicos, podemos citar o de Sérgio Gonçalves, "Processos de formação política e ideológica e a estruturação de territórios agroecológicos na Reforma Agrária paranaense". O Estado do Paraná é evidenciado e analisado a partir da constituição desses territórios, intencionando uma Reforma Agrária baseada em concepções diferenciadas de agricultura e atentando para as experiências no estado e sua importância na formação política para a consolidação desses territórios.

Como se vê, alguns trabalhos assinalam a utilização da Agroecologia como forma de territorialização e autonomia dos assentamentos, levando em consideração a importância dessa produção principalmente para a resistência dessas populações.

Todos os artigos demonstram as diferentes perspectivas dos movimentos em relação à Agroecologia e sua importância para a agricultura familiar, e esses trabalhos ocupam posição de destaque nos eventos. Um exemplo que abrange a discussão como um todo é o trabalho de Márcio Freitas Eduardo, publicado na edição de 2010 do evento. Em "Agroecologia: teoria e poder", ele busca demonstrar que essa ciência pode se apresentar como revolucionária tanto no âmbito teórico como na práxis, possibilitando autonomia e legitimidade aos territórios.

Assim, os trabalhos dessa tipologia seguem duas vertentes: uma que analisa e apresenta experiências agroecológicas nos acampamentos e assentamentos, e outra pensada por um viés político-ideológico, que evidencia a importância desse tipo de produção na luta pela terra e pela reforma agrária. São quatorze trabalhos, sendo o tema um dos mais recorrentes nos eventos. Isso mostra como esses 
movimentos estão incorporando a discussão e entendendo a importância desse tipo de produção e as mudanças que ele acarreta nas relações de trabalho nos territórios.

\section{Agroecologia e Experiências e Estudos de Caso}

Reside aqui o maior número de trabalhos publicados nas seis edições analisadas: a descrição de experiências e estudos feitos em uma determinada localidade (comunidade, município, região ou estado), apontando as especificidades e a abrangência de projetos e estudos relacionados à Agroecologia em cada região do país.

Os trabalhos englobam desde comunidades pequenas de produtores regionais, mostrando, por exemplo, como a Agroecologia está sendo trabalhada no contexto das escolas municipais, até recortes maiores, como os estados da Paraíba e do Rio Grande do Sul. Nesses últimos trabalho houve um esforço dos pesquisadores em entender a dinâmica de todo o estado em relação a esse tipo de produção. Porém, a grande maioria trata dos municípios e de como essa produção se dá nas diferentes comunidades, se há ou não apoio etc.

Entre esses trabalhos, estão o de Giancarla Salamoni, Adão José Vital da Costa e Roberto Antônio Finatto, "Sustentabilidade e Agroecologia: experiências de associativismo com produtores familiares do Rio Grande do Sul", e o de Ana Paula de Medeiros Ferreira, Ana Paula da Silva de Oliveira e Marcelo Rodrigues Mendonça, “A Agroecologia no contexto escolar do município de Catalão (G0): resultados de uma experiência", nos quais se observa um esforço em descrever as experiências no estado e no município respectivamente, a fim de demonstrar a viabilidade e as especificidades da produção agroecológica em tais territórios a partir das experiências descritas.

Outro caso é o trabalho de Cesar Bruno Favarão e Flamarion Dutra Alves, "Agricultura familiar e Agroecologia: desenvolvimento e mercados na feira livre de Alfenas (MG)", que demonstra a viabilidade da comercialização dos produtos agroecológicos na feira - as dificuldades encontradas, 
como preço e transporte dos produtos, e os benefícios trazidos para os agricultores pela possibilidade de comercializarem seus produtos.

Alternativas de comercialização para determinados produtos locais também são descritas e analisadas. Citam-se as feiras agroecológicas e propostas de intervenção como sítios agroflorestais.

Além dos recortes municipal e estadual, muitos recortes regionais também são utilizados, como, por exemplo, determinadas regiões dos estados, principalmente no sul do país.

O grande número de publicações nessa tipologia retrata o crescimento das experiências alternativas de produção em todo o território nacional. Mostra que, apesar dos incentivos serem ínfimos e a capacidade do produtor em produzir agroecologicamente é por vezes diminuída, cresce em número e gênero a busca por diferentes formas de produção que sejam menos degradantes para o ambiente e a sociedade. A Agroecologia reestrutura os padrões de produção no sentido de reaver questões esquecidas pelo modelo de agricultura dominante, tanto ambientalmente como socialmente, economicamente e eticamente.

Podemos observar que as formas de trabalhar tais casos voltados às experiências e estudos de caso, mudam de acordo com as experiências, diferenciando-se no recorte espacial as possibilidades para uma maior inserção da agricultura sustentável em diferentes âmbitos da produção.

\section{Conclusões}

A partir da análise realizada, podemos identificar alguns pontos importantes na direção de uma mudança no cenário agrícola nacional.

Apesar de o Agronegócio intencionar a perpetuação de formas de produção que não condizem socialmente e ambientalmente com essa mudança, a Agroecologia, desde os anos 1980, vem demonstrando a necessidade da incorporação de novas políticas nacionais de apoio ao pequeno produtor. Esse produtor foi e está sendo expulso do campo devido ao crescimento das grandes lavouras 
produtoras de commodities de exportação. A produção desses produtos acaba por necessitar, além de grandes extensões de terra, um arcabouço de produtos químicos e maquinários pressupostos nos pacotes tecnológicos, algo que muitas vezes o agricultor não tem condições de obter e que o leva a arrendar ou mesmo vender sua terra para grandes latifundiários e empresas.

Somam-se ao esvaziamento do campo e ao supercrescimento das cidades o avassalamento dos solos, da vegetação, dos corpos d'água, a queda na qualidade dos produtos e o fim da soberania alimentar das populações do campo. Em suma, trata-se de uma condição social e ambientalmente exploratória, na qual o homem e o meio ambiente não precisam mais fazer parte da dinâmica ambiental, pois tudo fica por conta dos fertilizantes e agrotóxicos que retiram toda a capacidade do solo de se sustentar naturalmente. Portanto, a necessidade política de apoio ao pequeno produtor com vistas a produções sustentáveis é o que se pode observar nessa transição agroecológica pós-década de 1980, na qual identificamos um grande potencial de mudança para o cenário nacional.

Grande parte desse potencial se configura por meio da luta pela terra e pela Reforma Agrária no país. Muitas dessas experiências são reproduzidas e vistas como revolucionárias quando comparadas ao modelo predominante na agricultura. Ao analisarmos os trabalhos publicados nos eventos, podemos observar como a tipologia que abarca essas experiências é bastante representativa diante do todo.

Ao destacarmos os principais autores citados nos eventos e as palavras-chave mais utilizadas, mostramos que a quantidade de autores que trabalham a temática vem aumentando, que a Geografia não está deixando de lado as discussões acerca dessa nova transição agroecológica, e que há diferentes temas e perspectivas geográficas na discussão.

O número de trabalhos publicados ilustra o crescimento exponencial das publicações sobre Agroecologia no Encontro Nacional de Geografia Agrária. Mostra, assim, que a Geografia pode e deve fazer essa inter-relação não só com a ciência agroecológica, mas com as diferentes áreas do conhecimento, a fim de auxiliar na justiça social e no desenvolvimento sustentável. Destaca-se aqui a capacidade da Geografia em analisar tais processos, apresentando-se como uma das grandes responsáveis pela mudança de paradigma proposta. 
As tipologias definiram os diferentes modos de discussão e relação entre as duas ciências, e nos permitiram, entre outras coisas, ter acesso à descrição de experiências em diferentes territórios vinculados a condições socioespaciais diversas, o que reforça o caráter geográfico da discussão.

Outro aspecto importante observado foi a educação ganhando cada vez mais espaço nessas discussões, esteja ela vinculada ao campo, onde se faz mais necessária visto que é ali que esses processos ocorrem, ou não, com trabalhos discutindo a educação ambiental e o desenvolvimento sustentável nas cidades. Portanto, foi grande a representatividade quantitativa e qualitativa da Agroecologia nas edições analisadas. O que se observa é justamente a falta de suporte para a viabilização das políticas e programas de apoio a atividades que não estejam ligadas ao Agronegócio. As diretrizes do MAPA ilustram este aspecto e confrontam-se com as do MDA, que apresenta propostas e ações para a agricultura familiar e sustentável. Porém, historicamente prevalecem no espaço agrário brasileiro as propostas do primeiro tipo.

Apesar de os trabalhos pontuarem um cenário promissor tanto para a ciência geográfica como para a agricultura brasileira, o que falta para as demais formas de produção agrícola é aquilo que sobra ao Agronegócio nacional: o apoio governamental e político das diferentes esferas de poder, além da integração entre elas, oferecendo oportunidades e viabilizando a produção a partir de diferentes perspectivas.

\section{REFERÊNCIAS}

ALTIERI, M. A. Agroecologia: as bases científicas da agricultura alternativa. Rio de Janeiro: PTA, 1989.

ALTIERI, M. A. Agroecologia: A dinâmica produtiva da agricultura sustentável. 5. ed. Porto Alegre: UFRGS Editora, 2004.

BALESTRO, M. V. (Org.). Agroecologia: os desafios da transição agroecológica. São Paulo: Expressão Popular, 2009. p. 7 16 .

CHELOTTI, M. C. Agroecologia em assentamentos rurais: estratégia de reprodução camponesa na Campanha Gaúcha (RS).

Agrária: revista do laboratório de Geografia Agrária. USP. São Paulo, v.7, p.94-118, jul/dez 200 
ELIAS, D. Globalização e agricultura: a região de Ribeirão Preto - SP. São Paulo: Edusp, 2003. 400 p.

EMBRAPA. Marco referencial em agroecologia. Brasília/DF, maio de 2006.

GRAZIANO DA SILVA, J. A nova dinâmica da agricultura brasileira. Campinas: Unicamp, 1996.

GRAZIANO DA SILVA, J. G. A modernização dolorosa: Estrutura agrária, fronteira agrícola e trabalhadores rurais no Brasil. Apresentação de: Otávio Guilherme Velho 2. ed. Rio de Janeiro: Zahar, 1981. 192 p.

GRAZIANO DA SILVA, J. G. O que é questão agrária. 12. ed. São Paulo: Brasiliense S.A., 1980. 114 p.

HESPANHOL, R. A. M. Agroecologia: limites e perspectivas. In: ALVES, A. F.; CARRIJO, B. R.; CANDIOTTO, L. Z.

P. (Org.). Desenvolvimento Territorial e Agroecologia. São Paulo: Expressão Popular, 2008. p. 117-136.

INSTITUTO BRASILEIRO DE GEOGRAFIA E ESTATÍSTICA - IBGE. Censo Demográfico 2010. Disponível em: $<$ http://www.ibge.gov.br>. Acesso em: dez. 2015.

INSTITUTO BRASILEIRO DE GEOGRAFIA E ESTATÍSTICA - IBGE. Informações Gerais. Disponível em: $<$ http://www.ibge.gov.br>. Acesso em: dez. 2015.

KUHM, T. S.. A estrutura das revoluções científicas. 9. ed. São Paulo: Perspectiva S.A., 2006.

MENDES, Heitor Nascimento. A perspectiva agroecológica em Geografia: análise a partir do Encontro Nacional de Geografia Agrária (ENGA). 2015. 60 f. TCC (Graduação) - Curso de Geografia, Instituto de Geografia, Universidade Federal de Uberlândia, Uberlândia, 2016. Cap. 3. CD-ROM.

MENDONÇA, M. R. A urdidura espacial do capital e do trabalho no Cerrado do Sudeste Goiano. 2004. 459f. (Doutorado em Geografia)- Faculdade de Ciência e Tecnologia, Universidade Estadual Paulista, 2004.

MINISTÉRIO DA AGRICULTURA. Informações Gerais. Disponível em: < http://www.agricultura.gov.br/> Acesso em: dez. 2015.

MINISTÉRIO DO DESENVOLVIMENTO AGRÁRIO - MDA. Informações Gerais. Disponível em: <http://www.mda.gov.br/sitemda/> Acesso em: dez. 2015.

OLIVEIRA, A. U. de. A agricultura camponesa no Brasil. 2. ed. São Paulo: Contexto, 1996. 164 p.

OLIVEIRA, A. U. de. Modo capitalista de produção e agricultura. São Paulo: Ática S.A, 1986. 88 p.

PRIMAVESI, A. M. Agroecologia: práticas e saberes. Conferência de Abertura do I Simpósio Sobre Agroecologia do Sudeste Goiano, realizado em abril/2007 na UFG/Campus Catalão.

SCHMITT, C. J. Transição agroecológica e desenvolvimento rural: um olhar a partir da experiência brasileira. In: SAUER, S,; BALESTRO, M. V. (Org.). Agroecologia e os desafios da transição agroecológica. São Paulo: Expressão Popular, 2009. Cap. 5. p. 177-203. 